\title{
DESIGN OF A COASTAL PROTECTION SCHEME FOR ADA AT THE VOLTA-RIVER MOUTH (GHANA)
}

\author{
Mark Bollen ${ }^{1}$, Koen Trouw ${ }^{2}$,Frederik Lerouge ${ }^{3}$, Vincent Gruwez ${ }^{1}$,Annelies Bolle ${ }^{1}$, Bernhard \\ Hoffman $^{4}$, Gert Leyssen $^{1}$, Yann De Kesel ${ }^{1}$, Peter Mercelis ${ }^{1}$
}

\begin{abstract}
The coastal town Ada in Ghana is threaded by a severe coastal erosion. A protection scheme has to be designed to protect the town. Since the area is ecologically important, e.a. due to the presence of turtles, both during the design process and during the construction phase actions to diminish possible negative effects have to be considered. The design is supported by measuring campaigns and numerical modeling of the currents, waves and morphology.
\end{abstract}

Keywords: coastal erosion, protection schemes, environmental monitoring

\section{INTRODUCTION}

Ada Foah is a coastal town located in the Dangbe East District of the Greater Accra Region of Ghana, about $100 \mathrm{~km}$ from Accra, the capital city of Ghana. It is situated near the Volta River estuary, in between the Volta River, Songor wetlands and the Atlantic Ocean.

Severe coastal erosion, causing loss of property and frequent inundations requires immediate action to prevent further damage. Before the construction of the Akosombo Dam in 1963, the Volta River transported 1 million $\mathrm{m}^{3}$ sand per year to the coast, resulting in a dynamic river delta. Following construction however, the coastline eroded more than $150 \mathrm{~m}$ and the river mouth tends to close (with numerous human and ecological consequences). The project aims at providing appropriate coastal protection.

\section{SITUATION}

Ada is situated at the mouth of the Volta estuary (Figure 1). The Volta estuary has a catchment area of $400.000 \mathrm{~km}^{2}$. In 1963 the Akosomba dam was completed. The dam was constructed for the generation of electricity. Before the construction of the dam, the mean water discharge was about $1000 \mathrm{~m}^{3} / \mathrm{s}$, with peaks of $6000 \mathrm{~m}^{3} / \mathrm{s}$. The yearly sediment transport was estimated at $7.5 \mathrm{million} \mathrm{\textrm {m } ^ { 3 }} / \mathrm{s}$ (of which about $20 \%$ sand). Since the construction no peaks in flow discharge occur anymore and the sediment transport is reduced to only a fraction of the original transport. (EC, 1989)

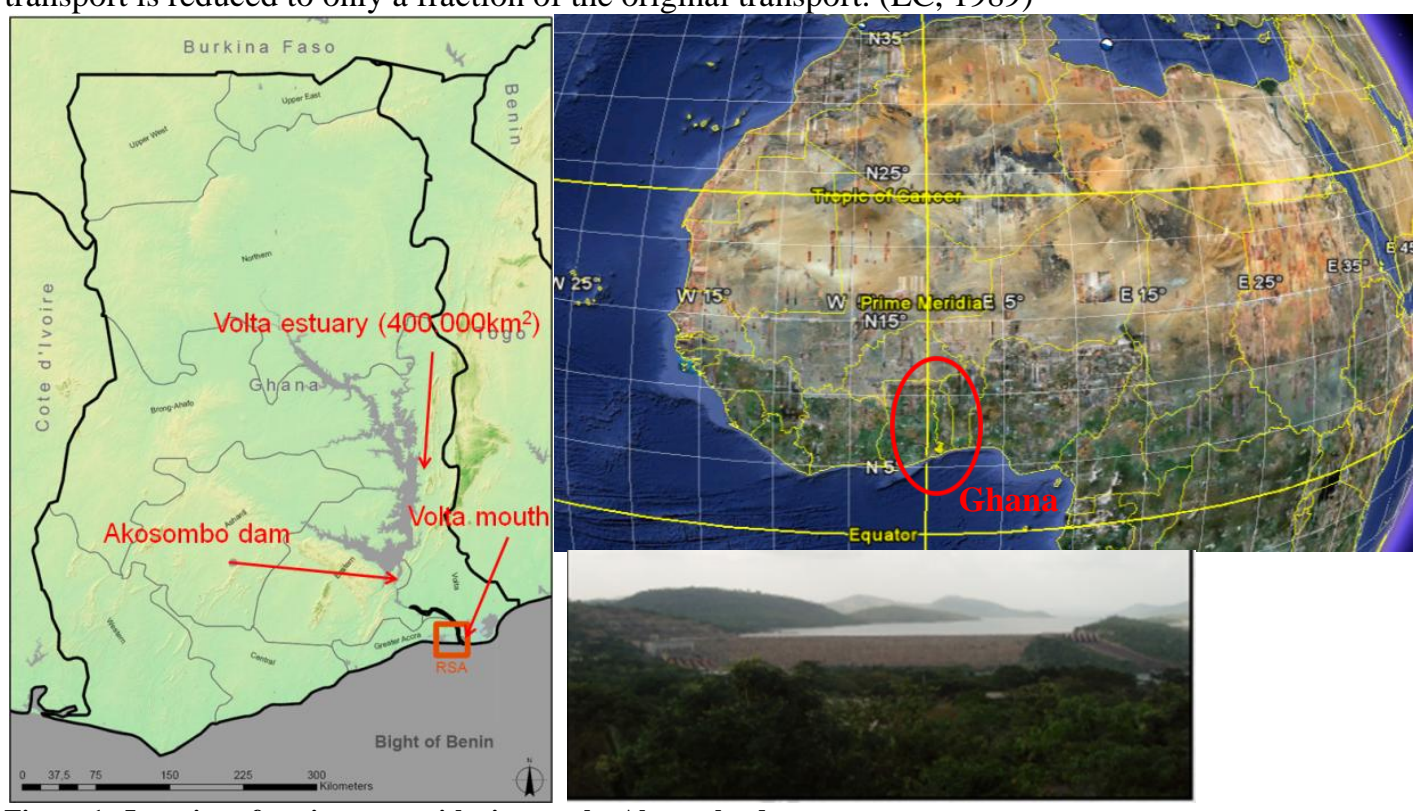

Figure 1 Location of project area with view on the Akosomba dam

\footnotetext{
1 IMDC, Belgium, Mark.Bollen@imdc.be

2 Fides Engineering, Belgium, Koen.Trouw@fidesengineering.be

${ }^{3}$ Ecorem, Frederik.Lerouge@ecorem.be

4 PMI, Ghana, Bernhard.Hofmann@pmi-Itd.co.za
} 
Due to the large sediment transport and the occurrence of peak discharges the Volta River delta was very dynamic before 1963. The sand spit was breached during peak flow discharges (storms) resulting in a cut off of the sand spit and hence erosion of the sand spit. Once the breach closed up again, sand supply to the sand spit resulted in growth again. This dynamic cycle is observed by Alkyon (1998) based on historical bathymetrical charts (Figure 2).

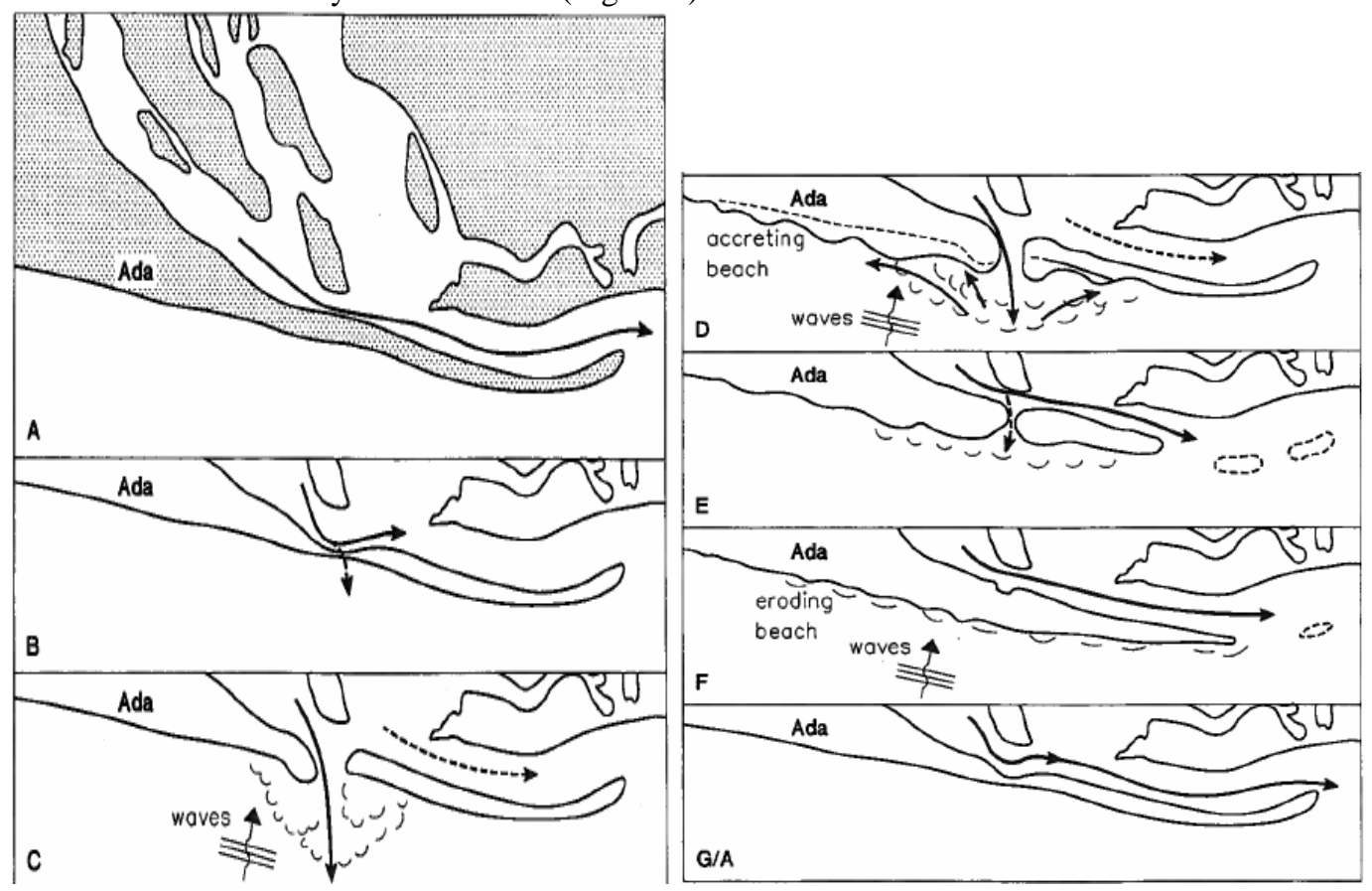

Figure 2 Dynamic evolution of the river mouth before 1963 (Alkyon, 1998, based on historical maps)

Since the construction of the dam it is observed that the coastal erosion increased significantly, also at locations upstream the mean alongshore (wave driven) current (=west of the Volta-river mouth). Figure 2 shows the coastline of 1974 (orange) and 2008 (black), the eroded area is indicated in red and the disappeared houses with red dots. The yearly retreat of the coastline is about $6 \mathrm{~m} / \mathrm{year}$ and destroyed a lot of buildings. The severe erosion has also other negative effects like disappearing roads, abandoned housing near the retreating coastline, steep erosion cliffs, ...

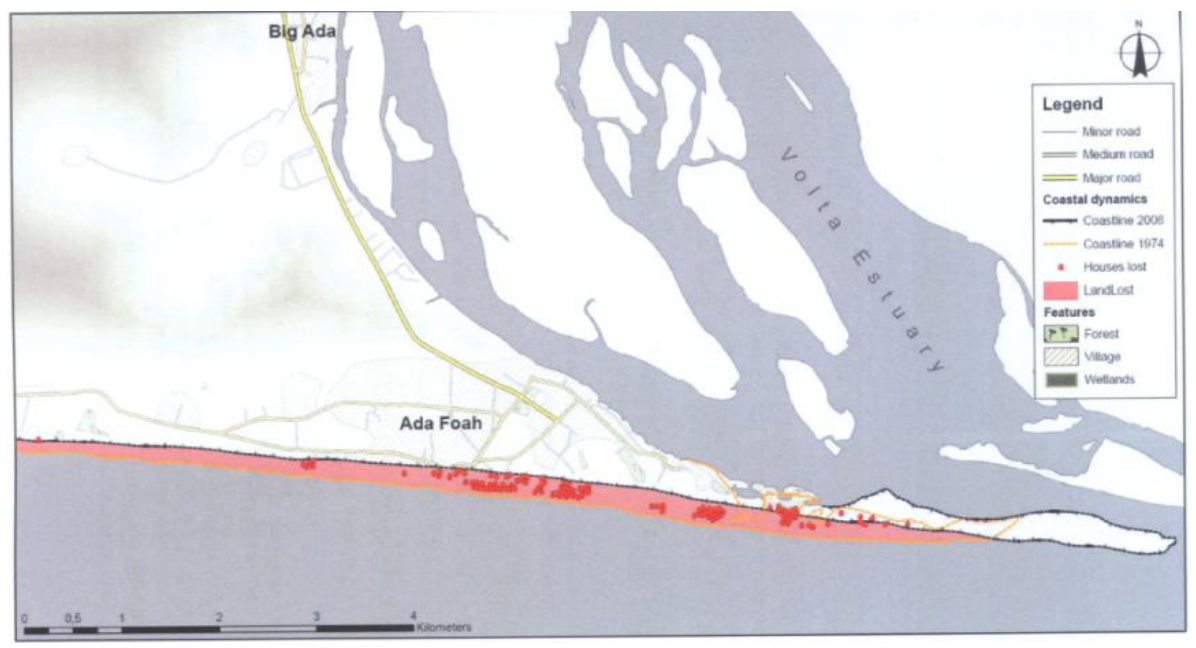

Figure 3 Coastal erosion over the last decades with loss of buildings and growth of the sand spit in the river mouth 


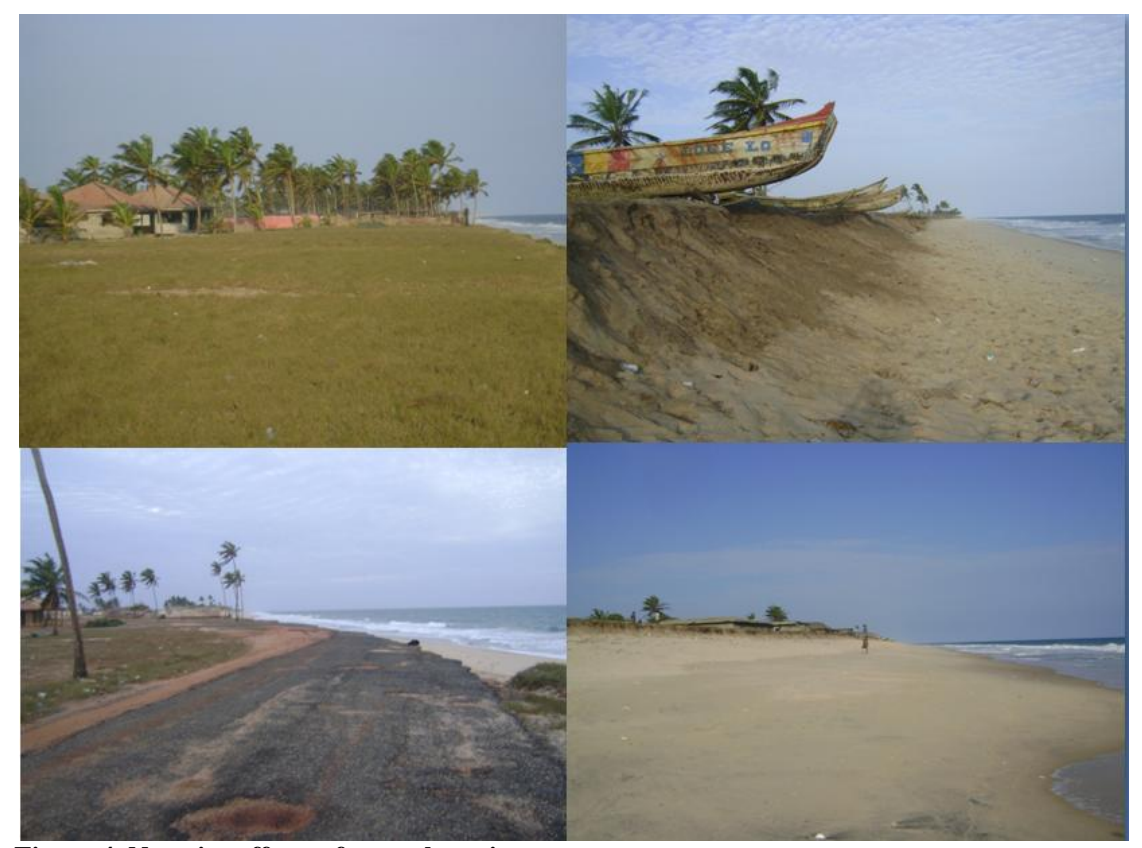

Figure 4 Negative effects of coastal erosion

Together with the erosion, the sand spit is growing and tends to almost close the Volta-estuary. Sometimes the sand spit is eroded during severe storms, but when the mouth becomes too small a channel is dredged through the spit. If the exchange of (salt) water is too small the problem of the Bilharzia disease increases (the larvae grow best in calm, fresh/brackish water). It is observed that the dredged channel moves eastward (in the direction of the longshore current) and closes completely after about 3 years.

\section{MEASUREMENTS}

A bathymetry survey was performed in the estuary and at near-shore locations along the coastline (up to $-10 \mathrm{~m}$ LAT). A beach profile is shown in Figure 5.The beach is steep (up to 1:8) above 0 LAT and rather flat $(1: 100)$ below $-4 \mathrm{~m}$ LAT. Surveying the surf zone was impossible due to the persistent wave climate.

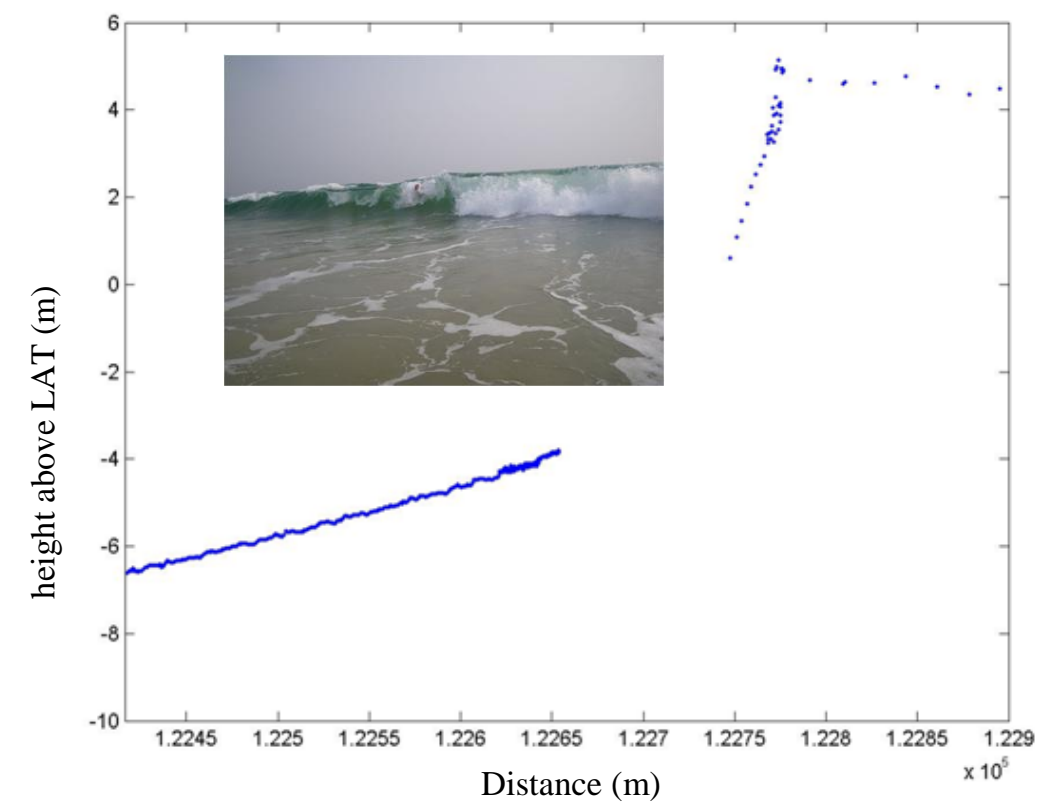

Figure 5 Cross shore profile - measuring conditions in the critical zone

Throughtide measurement campaigns of the discharge and flow rates at the tidal inlets were also executed (measuring locations are shown in Figure 6). This data gave an indication of the tidal prism, which is difficult to estimate since it is hardly know how much water flows in the mangrove areas. The 
water level measurements (Figure 7) show that over the first $5 \mathrm{~km}$, where the estuary is very wide, the tidal amplitude hardly decrease (only $10 \mathrm{~cm}$ ), but in the river itself, the amplitude decreases fast $(60 \mathrm{~cm}$ over $20 \mathrm{~km})$.
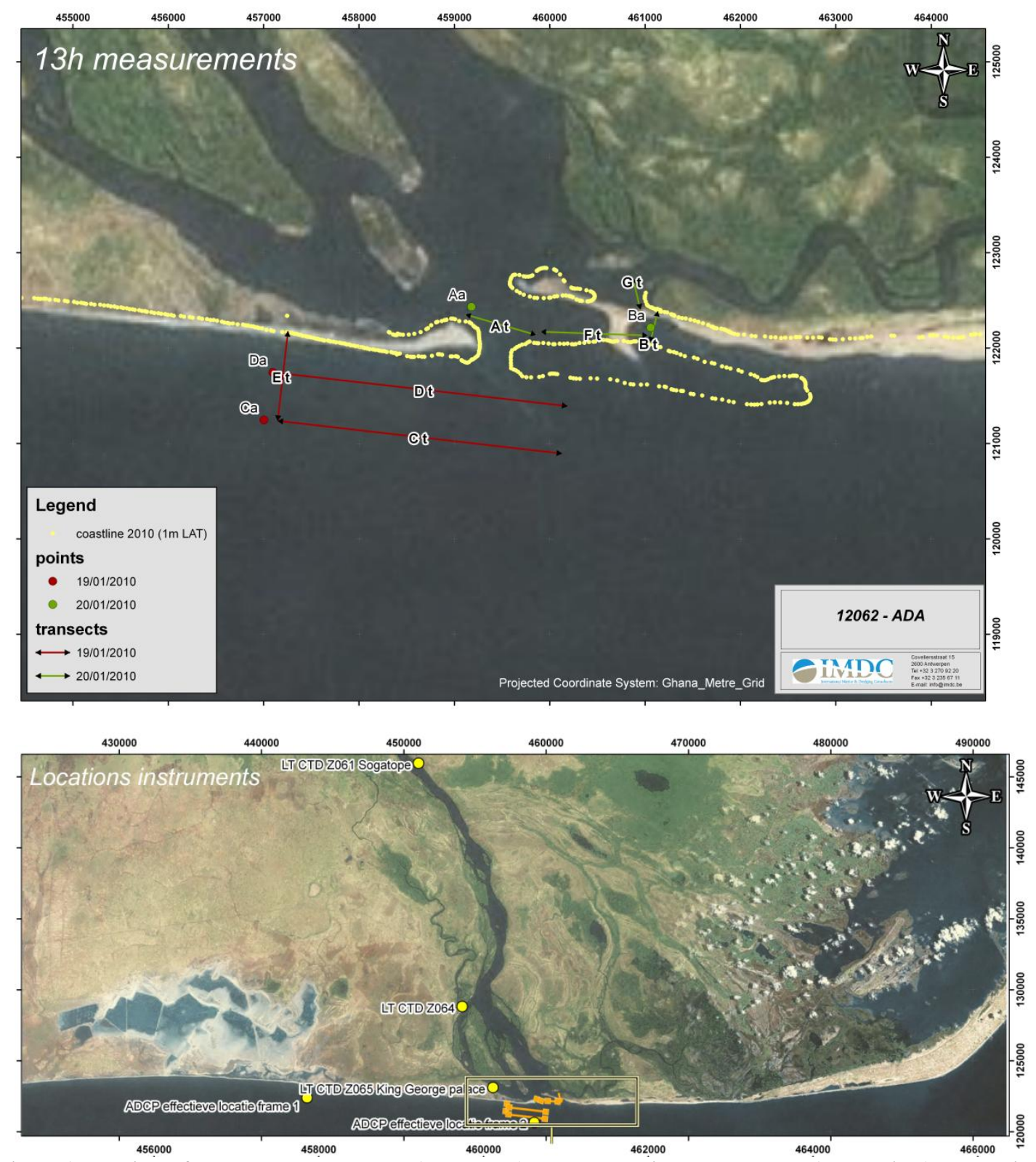

Figure 6 Locations of long term measurements (yellow dots) and through tide measurements (orange lines) and detail of the through tide measurements above 


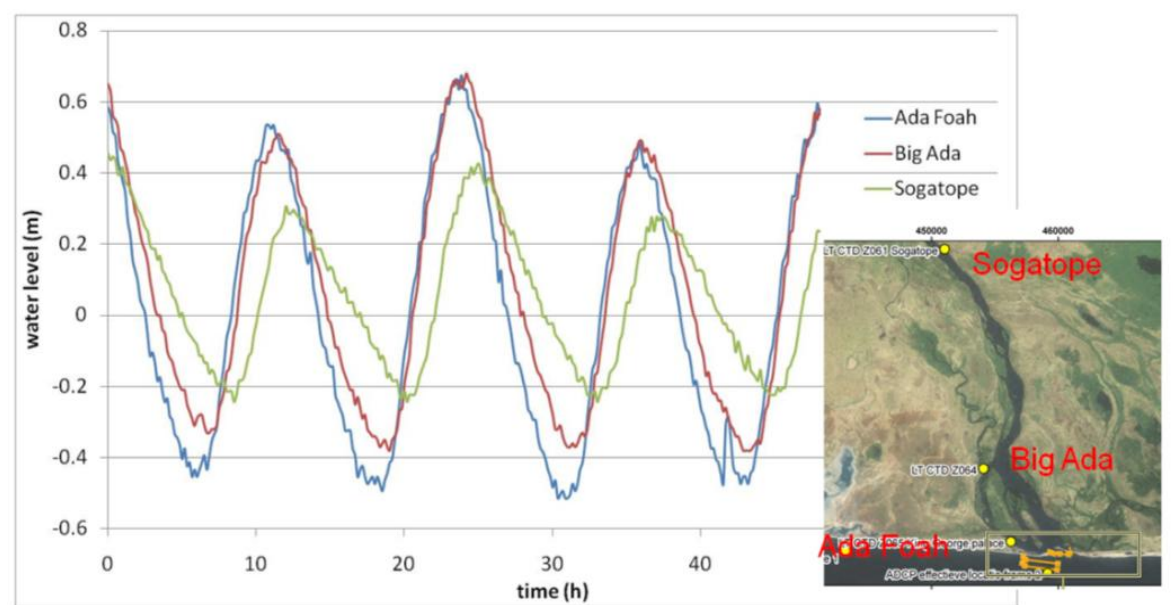

Figure 7 Water levels in the Volta estuary

The analysis of the grain sizes (Figure 8) shows well sorted coarse sediments, with the finest sediments at the river mouth.

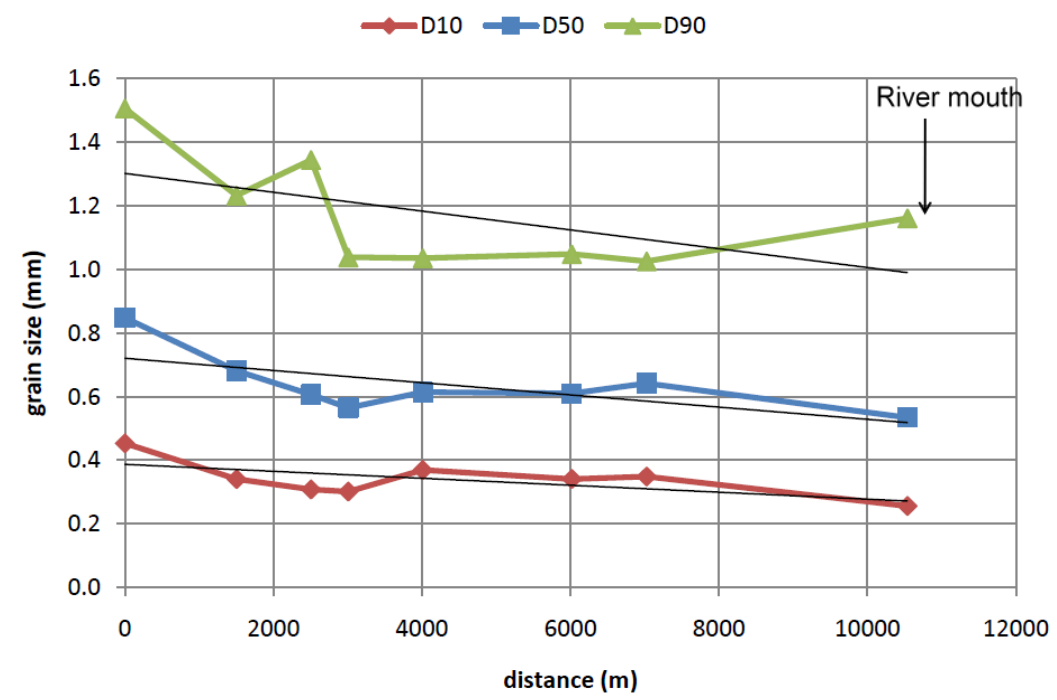

Figure 8 Grain sizes west of the Volta mouth

\section{NUMERICAL MODELLING}

Different numerical models are used to investigate the erosion problem, to generate boundary conditions for design and to evaluate possible design schemes.

Delft3D is set up to investigate the (effect of) currents along the coast and to investigate the behaviour of the mouth. For the calibration, the different measurements are used: comparison of discharges, water levels in the estuary and the velocities at sea. 

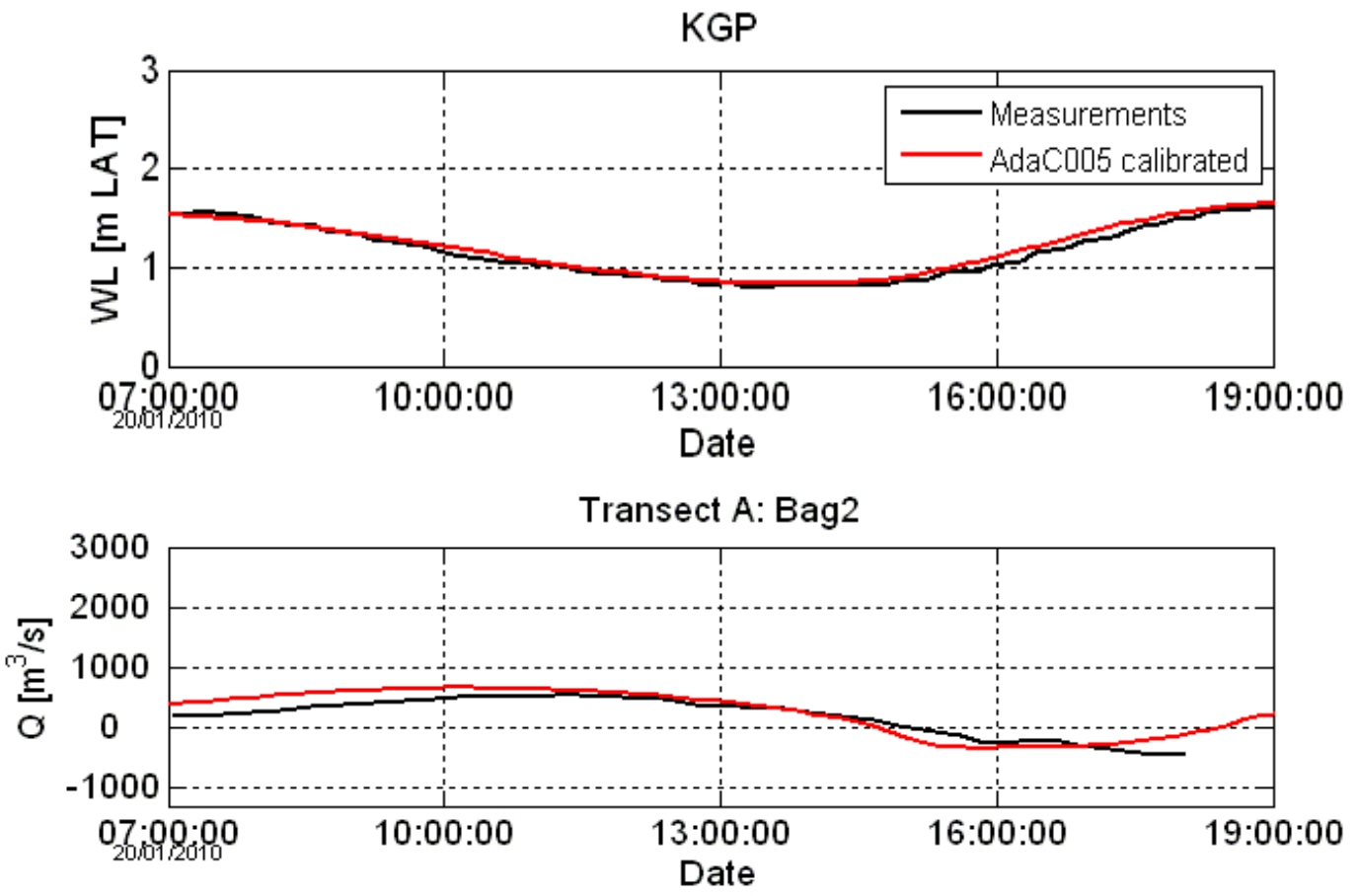

Transect B

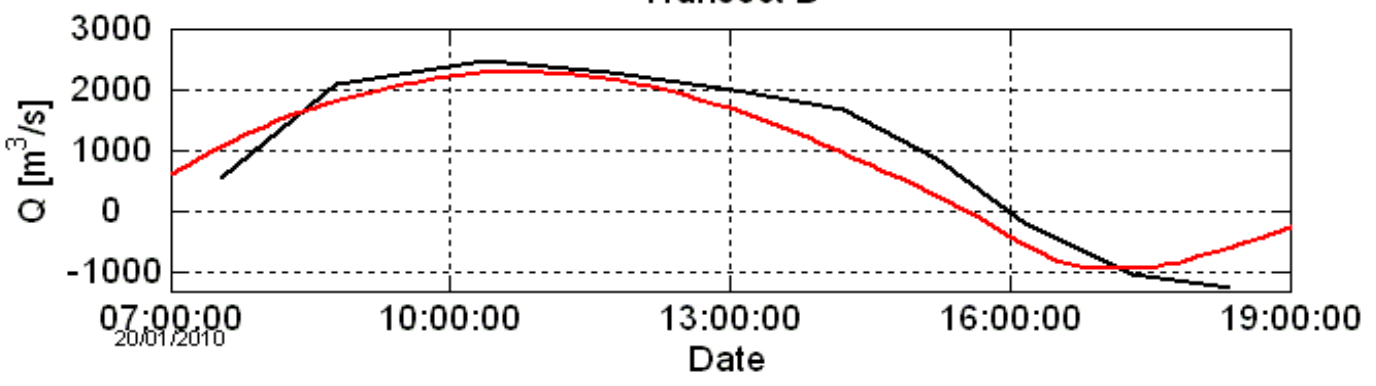

Figure 9 Calibration with the discharge at the mouth

A time series of 16 years of hindcasted wave data (derived from ECMWF wave spectra calibrated by Oceanor with satellite altimeter measurements) are transformed from offshore to nearshore by means of a transformation matrix put up with SWAN. Because the wave energy is almost always composed of wind sea and swell, with different wave periods, the wave spectra first had to be split into different components (e.g. Figure 10). It was found that the offshore wave climate is dominated by swell originating from southern directions and that multiple swell components are often present, with peak wave periods of $10 \mathrm{~s}$ and even up to $20 \mathrm{~s}$. 

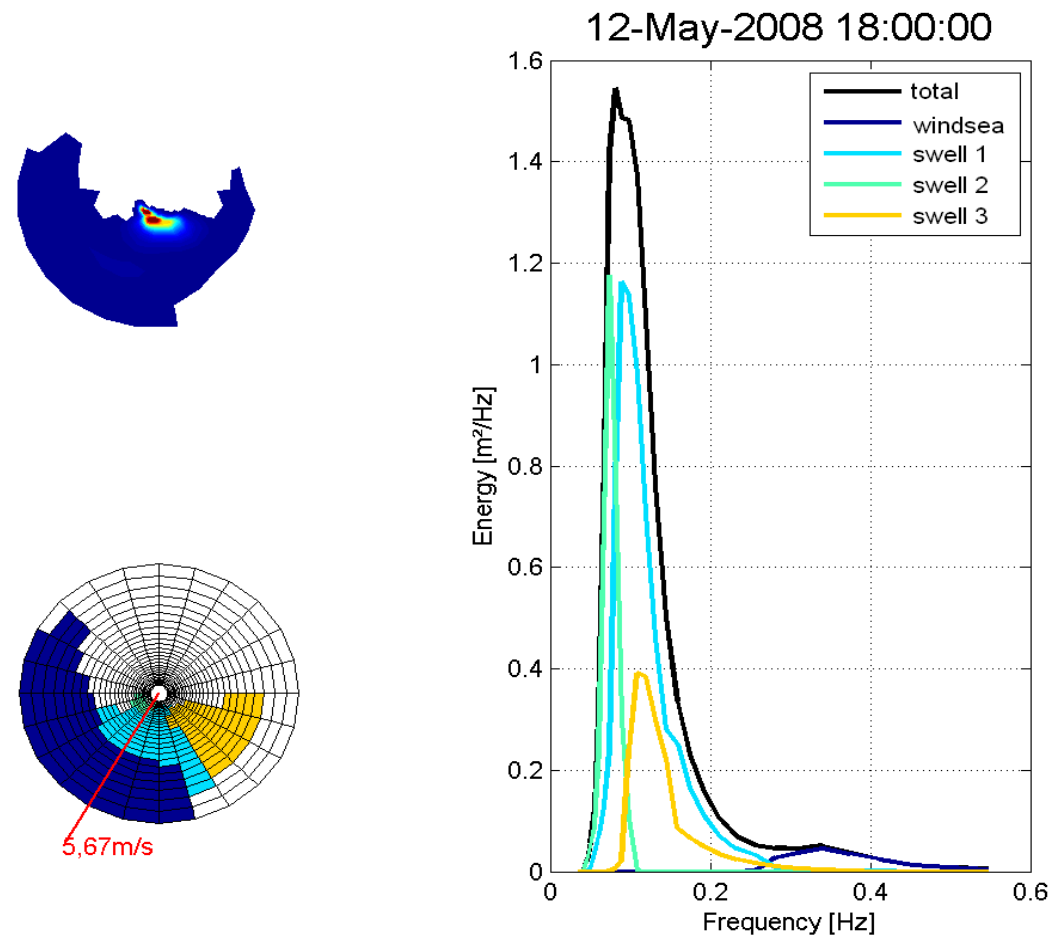

Frequency $[\mathrm{Hz}]$

Figure 10 Example of the separation of the wave spectra into the different wave components

The different components are transformed separately to nearshore with the transformation matrix. For a certain nearshore output location, time series for each component are obtained, which can be superposed to obtain one time series of wave heights, wave periods and directions. With this information, wave roses are constructed. The nearshore wave direction was almost always situated between SW and SSE (Figure 11).

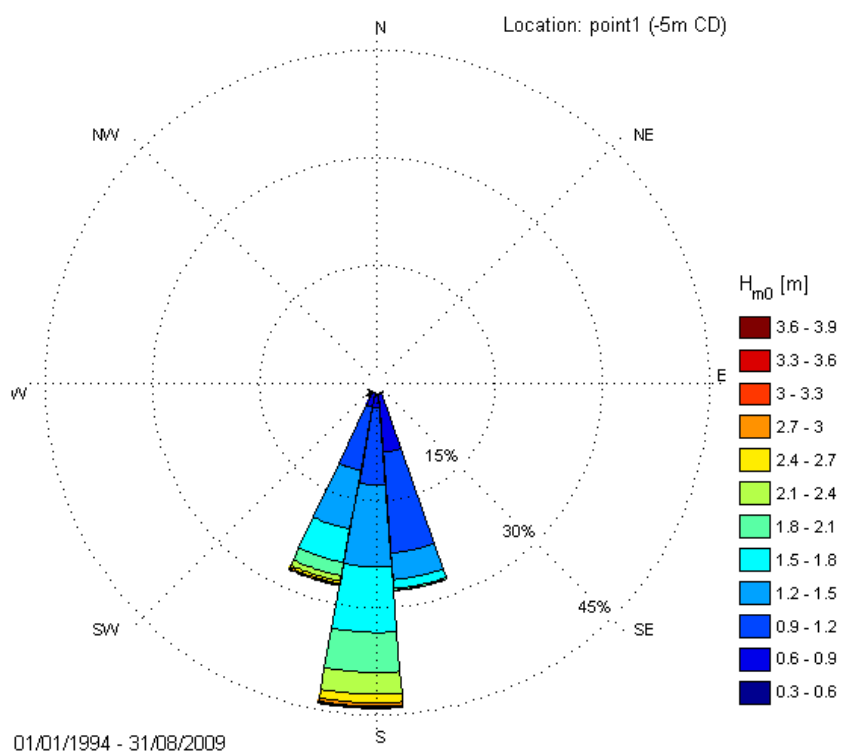

Figure 11 Wave rose at a nearshore location close to Ada. Peak wave directions per sector of $15^{\circ}$, centered around the coast normal $\left(=\mathbf{1 8 3}^{\circ} \mathrm{N}\right)$.

\section{BASIC DESIGN}

The proposed structures and beach nourishment in the preliminary design are shown in Figure 12.

Other alternatives that are taken into account are:

- A groyne system with equally spaced and equally long groynes.

- A groyne system with groynes of increasing length towards the east. 


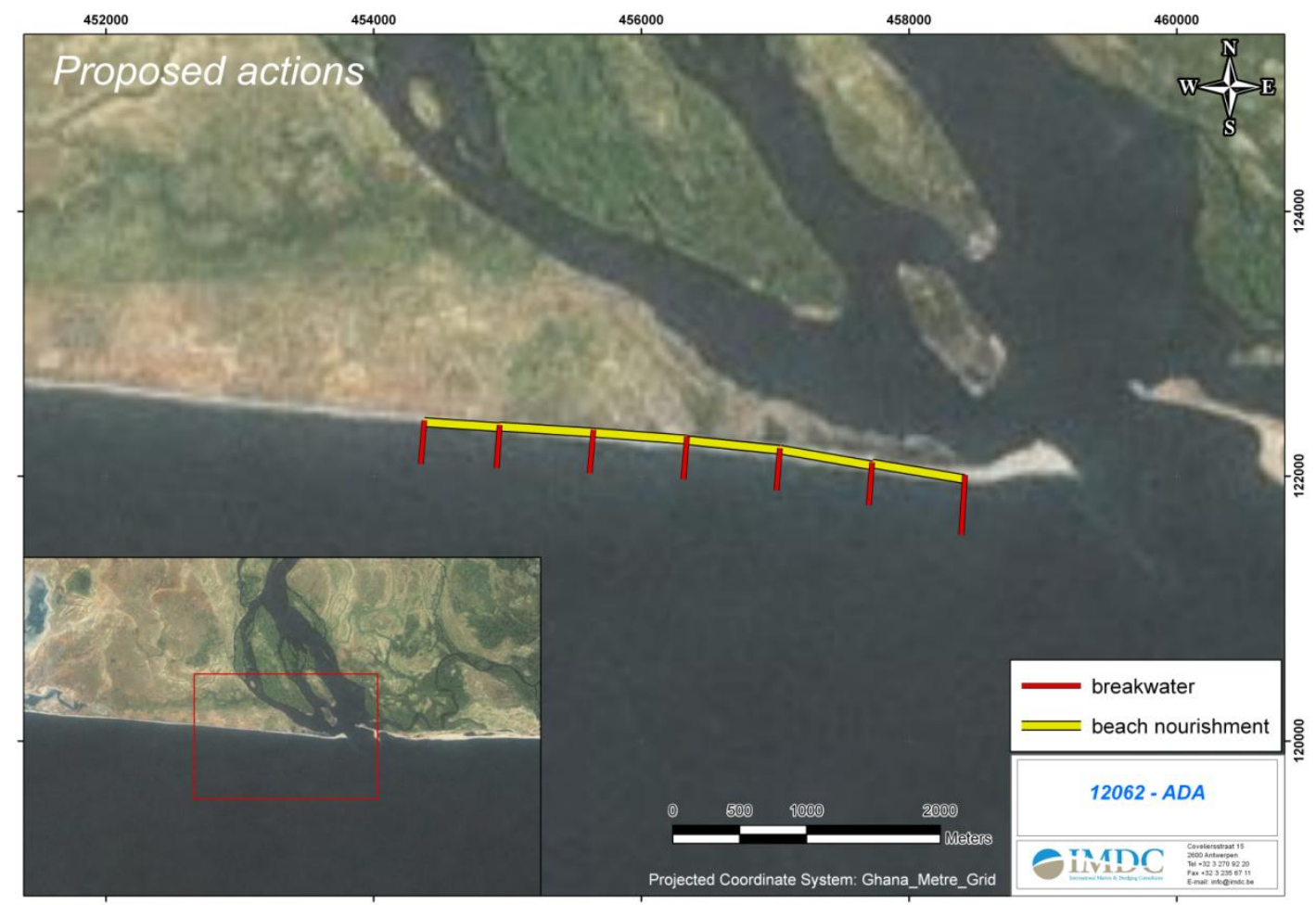

Figure 12 Proposed structures, beach nourishments and sand mining zone

For the design of the groynes, beside theoretical rules, following practical aspects had to be considered: Availability of sufficient big stones (8-10 ton), taking into account the high abrasion values of the material in nearby quarries which are normally only supplying the building industry;

The very long swell (peak wave periods of $10 \mathrm{~s}$ and up to $20 \mathrm{~s}$ ) which makes working at sea very difficult;

Occurrence of high waves and undertow which results in high losses during the construction of the core.

The beach had to be designed to provide sufficient protection against flooding, while avoiding very steep beaches which might cause issues for boat landing and turtle nesting.

Increasing the length of the groyne near the estuary traps more sediment in the project area but could increase erosion of the sand spit (turtles) and the other side of the mouth (also villages), so an optimisation is necessary. The length of the other groynes has to be long enough to get a "maintenance free" solution For the nourishment the profile should not be too steep (fishermen, turtles)and available sand from the estuary will be used.

\section{ENVIRONMENTAL IMPACT STUDY}

The environmental impact study demonstrated a.o. the importance of the Ada Foah beach and sand spit for sea turtle nesting. Given the protected status of these animals and the relative importance of this beach for nesting, the final design needs to incorporate this ecological aspect in order to avoid permanent loss of nesting ground. Extensive monitoring and prevention is also foreseen.

\section{Monitoring concept}

First, in order to be able to draft a successful prevention and mitigation plan, one first needs to know the characteristics and distribution of turtle nesting efforts in the project area. This is done by surveying turtle populations over a number of nesting seasons, and over at least the entire coastal stretch that will be affected, prior to the actual works. The main goal of this monitoring is to obtain insight in the nesting population of the project area as a whole. Ideally, long-term time series of nesting incidence are 
used, allowing for trends and 'natural' variation to be taken into account. Ongoing monitoring efforts of the local Wildlife Division a.o. allow for comparison of results over several years.

Second, site-specific knowledge on distributions and local variations of sea turtle nesting efforts allow for the design of an adapted prevention and mitigation strategy. This too, includes monitoring. However, this time the monitoring takes place during the works, at a confined space, in function of prevention and mitigation only. The main goal of this monitoring is to observe individual turtle activity, and to be able to take quick and appropriate action at specific locations that are or will be affected.

\section{Sea turtle occurrence}

Three species (L. olivacea, C. mydas and D. coriacea) are currently nesting in Ghana (Owusu et al. ) All three species have been nesting on the Ada Foah beaches. The Green turtle however, has not been spotted for years, until one isolated occurrence during the 2009-2010 season(Ada Wildlife Division, pers. Comm.) Globally, Ada Foah has therefore two active nesting turtles the Olive Ridley and Leatherback, and one potential nesting turtle, the Green turtle.

During the Ecorem field visit campaign in early December 2009, turtle activity in the entire project area was mapped using GPS (Figure 13 and 14). All sea turtle tracks, nests, sightings, poached and hatched nests were recorded for each species separately. This inventory provided a highly detailed snapshot of the sea turtle activity during the peak of the nesting season. Also, the relative density of the nests was calculated in a GIS, providing a quantitative insight in nesting density at any given point on the coastline in early December 2009. Again, the heterogeneity of nesting activity is striking. With the newly dredged access channel in place, the coastline in the project area could be said to exhibit two sandspits, both of which are significantly more popular for turtles to nest on.

The intrinsic vulnerability of global sea turtle populations is stressed. Aside from natural phenomena such as predation, in the LSA the most common threats for sea turtles are the following (but most of these are universal):

- Poaching of eggs / hatchlings: Reportedly not done by the local people as they respect the turtles, but sometimes nests are poached by immigrants (mostly either from other countries of from the Volta Region) for consumption. This is illegal, and regular beach patrols are carried out (Ada Wildlife Dept., pers. Comm.);

- Predation by dogs: Used to be a major issue, but is now more or less under control by controlling the dog populations of Ada Foah;

- Beach erosion: high erosion rates lead to steep beach profiles, which cannot be taken by the turtles. This virtually renders a beach useless for nesting, as turtle nests need to be above the high water line;

- Traffic of ATVs on the beach: can destroy nests, boats can hit turtles, causing injury or death;

- Fishing / boat collisions: attributing to a significant amount of stranded turtles;

- Plastic: probably one of the most fundamental problems. Transparent pieces of plastic (e.g. from drinking bags) are eaten by turtles and cause digestive problems, leading to their death. As plastic is non-biodegradable, and massive amounts are littered in Ghana, this issue is of major concern.

Other aspects affecting turtle nesting are disturbance and light pollution. Each of these threatening processes is evaluated for the Ada Foah situation based on site-specific data and observations.

Because of the presence of nesting sites of Endangered and Critically Endangered species (i.e. sea turtles), monitoring before and during the works is advised. This monitoring campaign comprises two phases: 
1. An extensive monitoring of the coastal stretch covering the 'urgent phase' project area and the sand spit during the most recent nesting season: This should allow for the identification of nesting hotspots, and to adapt the project to the presence of the sea turtles. Also, based on these results and the comparison with monitoring results of previous years, a time series of nesting activities can be drafted and used to identify trends, af any.

2. Systematic monitoring during the groyne construction and beach nourishment to evaluate the presence of sea turtles and, if necessary, to take appropriate measures.

This monitoring campaign requires a site-specific design and approach. A detailed impact prevention plan is proposed in Ecorem(2010).

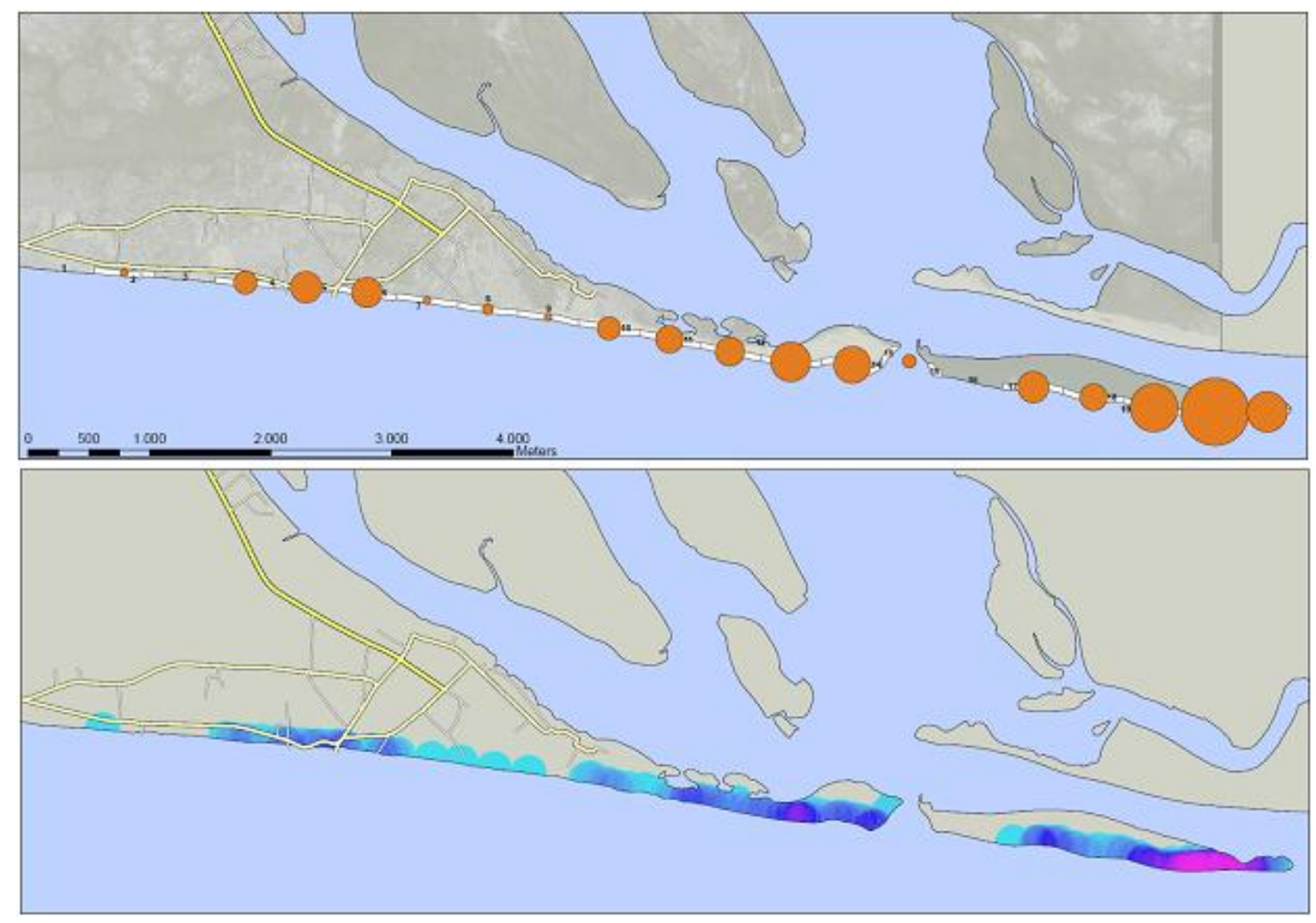

Figure 13: Observed turtle activity during the Ecorem field visit (early December 2009): point results (top) and density calculation (bottom). (c) Frederik Lerouge 


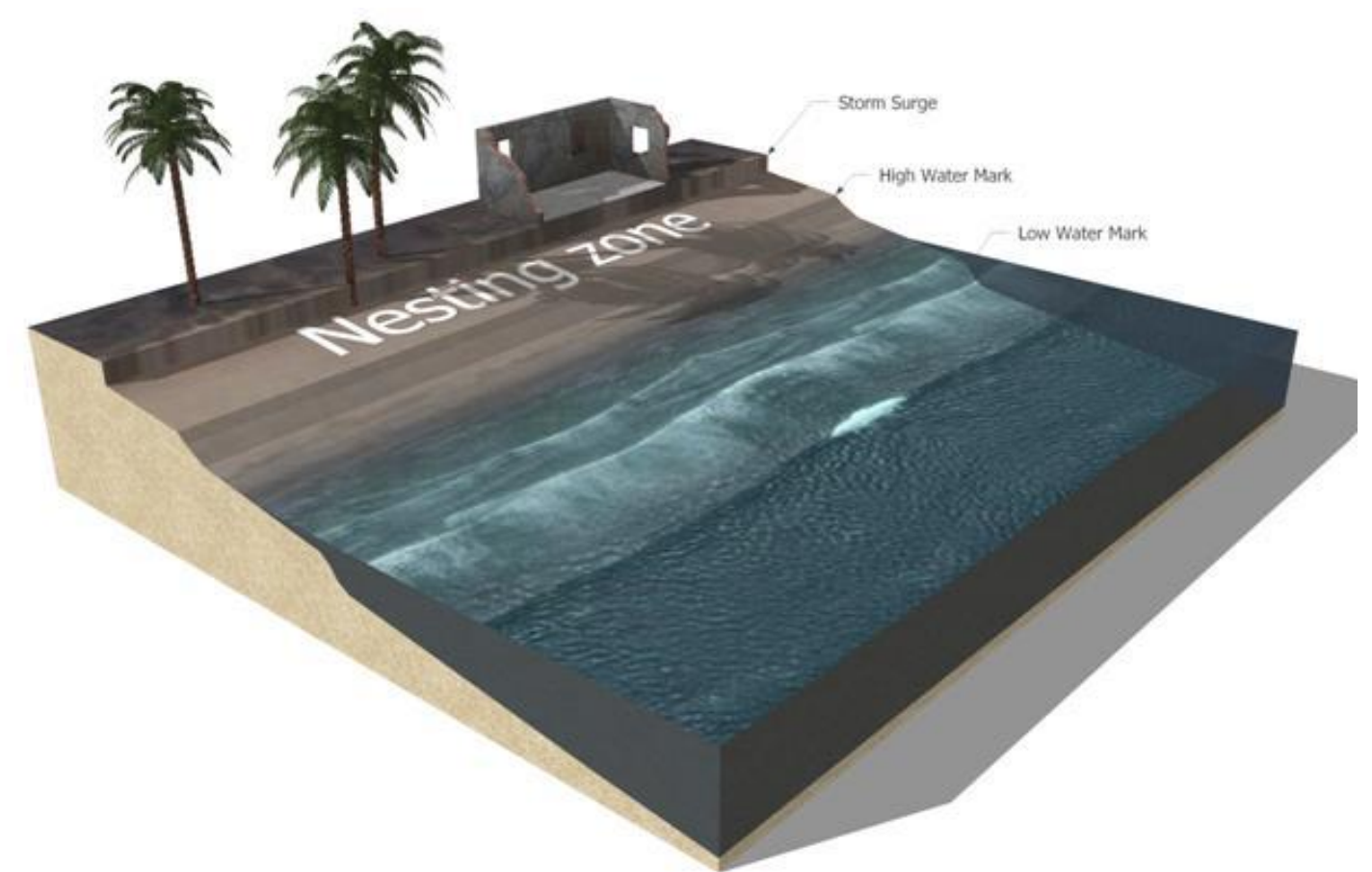

Figure 14 : Simplified diagram showing relative location of the nesting zone in Ada Foah (not to scale).(c) Frederik Lerouge

\section{FUTURE}

The whole Volta delta is threatened by floodings due to further erosion and sea level rise (cf. Figure 15, Boateng, (2009). Protecting the whole coastline is probably too expensive. For Ada a cost benefit analysis indicates that it is economically unviable to protect the houses, but by taking into account reduced (economical) growth (or worse) if uncertainty due to erosion remains, the analysis becomes positive. But this will not be the case for the whole area, and at most locations adaptive measures will be necessary.

An integrated water management plan for the Volta-delta is necessary. 


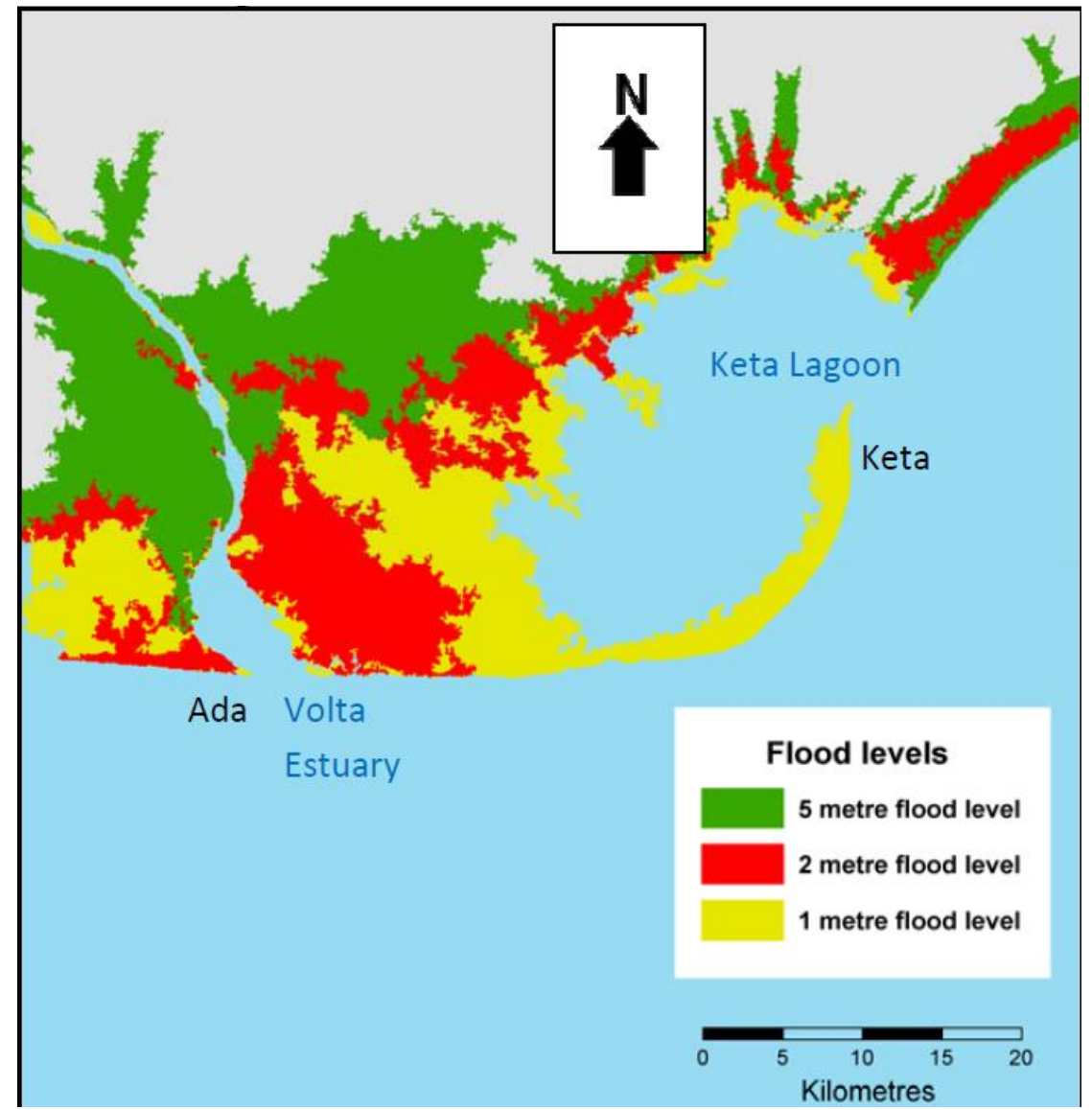

Figure 15: Flood levels in the Volta estuary with regards to sea level rise.

\section{ACKNOWLEDGMENTS}

The Government of the republic of Ghana (ministry of water resources, works and housing) is kindly acknowledge for the funding of this study.

\section{REFERENCES}

Alkyon. 1998. Sea defence Ada, Ghanam, report A208R3r1

Boatang, 2009, Development of Integrated Shoreline Management Planning: A Case Study of Keta, Ghana

EC, 1989, Coastal Erosion in the Bight of Benin - national and regional aspects. Report in commission by the European Community (project 6607.43.94.155)

Ecorem NV. 2010. Sea turtle monitoring for ADA FOAH Coastal Protection Project. - Monitoring proposal

Owosu et al, 2008, in Rees, A.F., Frick, M., Panagopoulou, A., Williams, K. 2008. Proceedings on the $27^{\text {th }}$ annual symposium on sea turtle biology and conservation. NOAA Technical Memorandum NMFS-SEFSC-569. US Dept of Commerce, Miami, USA. 298 pp. 